\title{
Post-traumatic stress disorder, survivor guilt and substance use - a study of hospitalised Nigerian army veterans
}

G T Okulate, MB ChB, FWACP, FMCPsych

O B E Jones, BSc (Psych), MSc (Psych)

68 Nigerian Army Reference Hospital, Yaba, Lagos,

Nigeria

Objectives. To investigate the prevalence of post-traumatic stress disorder (PTSD) and survivor guilt in a sample of hospitalised soldiers evacuated from the Liberian and Sierra-Leonean wars in which Nigerians were involved as peace keepers. The relationships between PTSD, survivor guilt and substance use were also investigated.

Design. A socio-demographic data questionnaire, the PTSD checklist and a validated World Health Organization substance use survey instrument were used to obtain data from the subjects.

Setting. The study took place at the 68 Nigerian Army Reference Hospital, Lagos, Nigeria, which was the base hospital for all casualties from the Liberian and SierraLeonean operations.

Subjects. All hospitalised patients from the military operations during a 4-year period (1990 - 1994) who were physically capable of being assessed were included in the study.

Results. The prevalence rate for PTSD was found to be $22 \%$ and survivor guilt was found in $38 \%$ of the responders. PTSD was significantly associated with long duration of stay in the mission area, current alcohol use, lifetime use of an alcohol/gunpowder mixture, and lifetime cannabis use. Survivor guilt was significantly associated with avoidance of trauma-related stimuli but not duration of combat exposure.

Conclusions. Although the sample studied was specific, PTSD might be quite common and probably undetected 
among Nigerian military personnel engaged in battle in Liberia and Sierra-Leone. Detection of such persons through deliberate screening in military community studies should help to alleviate the symptoms since good intervention methods are now available. Primary prevention efforts with regard to alcohol and cannabis use should help to reduce the incidence of PTSD.

S Afr Med J 2006; 96: 144-146

Post-traumatic stress disorder (PTSD) is an anxiety disorder that may develop after exposure to a terrifying event/ordeal in which grave physical harm occurred or was threatened. Traumatic events that can trigger PTSD include personal assaults such as rape or mugging, natural or human-caused disasters, accidents, and military combat. In the Diagnostic and Statistical Manual of Mental Disorders, 4th edition (DSMM. ${ }^{1}$ PTSD is described as a syndrome that follows exposure to a stressor that would evoke significant symptoms of distress in almost everyone. PTSD symptoms include persistent reexperience of the trauma (for example, intrusive recollections), avoidance of trauma-associated stimuli, and hyperarousal (for example, hypervigilance and anger).

Several epidemiological studies have provided information on the prevalence of PTSD, the association between specific traumatic experiences and the development of PTSD, demographic correlates, and co-morbidity of PTSD and other disorders. Perhaps the largest and most influential of those studies was the US National Co-morbidity Survey (NCS) conducted by Kessler and colleagues ${ }^{2}$ which found a PTSD lifetime prevalence of $7.8 \%$ for the total sample. One of the few studies ${ }^{3}$ to adopt the more recent DSM-IV criteria found a current prevalence of $2.7 \%$ for women and $1.2 \%$ for men in a Canadian community sample.

Co-morbidity in PTSD is said to be the norm rather than the exception. For example, it has been reported ${ }^{4}$ that $99 \%$ of Vietnam veterans with chronic PTSD qualified at some stage for another DSM-III-R diagnosis, compared with $41 \%$ of those without PTSD. The most prevalent co-morbid disorders in that study were substance abuse or dependence (75\%), generalised anxiety disorder (44\%) and major depression $(20 \%)$. Also, in the NCS study ${ }^{2} 88 \%$ of men and $79 \%$ of women with chronic PTSD met criteria for at least one other psychiatric diagnosis
Guilt and self blame are well-known features of PTSD and depression and are itemised in DSM-IV' as 'excessive or inappropriate guilt (which may be delusional), and not merely self-reproach or guilt about being sick'. Guilt was thought to be very infrequent among Africans with depression, ${ }^{5}$ but more recent studies ${ }^{6,7}$ have shown that it is being more frequently encountered in clinical practice. In the literature, survivor guilt is usually mentioned as a feature of PTSD. In DSM-IV it is described as 'guilt about surviving when so many others did not or about the things one had to do to survive'. This was illustrated by Friedman ${ }^{8}$ who observed that guilt featured prominently among some Vietnam veterans and included not only survivor guilt with regard to close friends killed in combat, but also guilt about Vietnamese people, especially women and children, killed in the course of duty.

There is considerable evidence that the adverse consequences of combat (including PTSD) are much greater in countries engaged in armed conflict. ${ }^{9}$ African countries involved in ethnic and political violence, including Liberia and SierraLeone, typify the situation. Nigeria led a regional peaceenforcement military mission to both countries, co-ordinated under the umbrella of the Economic Community lof West African States) Monitoring Group (ECOMOG). Although the exact casulty figures are beyond the scope of this study, judging by the number of military personnel killed, wounded and missing in action during military operations in both countries, the intensity of combat could be described as moderate to severe.

As part of our ongoing investigation into the psychological sequelae of the Liberian and Sierra-Leonean operations amoung Nigerian soldiers, we decided to study PTSD and survivor guilt and their associated factors among veterans evacuated back home for medical reasons.

\section{Method}

The study took place at the 68 Nigerian Army Reference Hospital, Lagos, Nigeria, a 350-bed general hospital serving as the base hospital for casualties from Liberia and Sierra-Leone. The hospital has a psychiatric unit with inpatient, outpatient and consultation-liaison services. All hospitalised patients from the military operations during a 4-year period (1990 - 1994) who were physically capable of being assessed were included in the study. They were mainly patients in surgery, medicine and psychiatry units, but 
psychotic patients and those with intellectually incapacitating disorders were excluded.

After explaining the objectives of the study, consent was obtained from those willing to participate. Nigerian political circumstances at the time were sensitive and it was understandable that some patients declined participation despite the assurance of anonymity. At the time many people did not want to be seen to be critical of ECOMOG. Also, anonymity meant that incomplete responses were difficult to trace. On the whole, a total of 1131 responses were judged adequate for analysis.

The first part of the questionnaire recorded socio-demographic characteristics of the subjects. The second part enquired about the experience of terrifying circumstances including war, armed robbery, road traffic accidents, imprisonment, torture and witnessing the death of others. PTSD was assessed using items from the PTSD checklist. ${ }^{10}$ Apart from direct experience of the trauma, items included in the questionnaire concerned re-experiencing the trauma in the form of intrusive recollections and/or dreams, hyperarousal symptoms and avoidance of places or circumstances that reminded the subjects of the unpleasant events. A 'no' or 'yes' response was required for each question; three positive responses were necessary to indicate that a respondent had PTSD. The presence of guilt was assessed by asking: 'Do you think you should have died or suffered in the place of the other persons who died?'

The final part of the questionnaire enquired about past and current use of substances, including alcohol, a local brew (kinjus) and gunpowder concoction, and cannabis, using items from a World Health Organization (WHO) substance abuse survey questionnaire that had been previously validated in Nigeria. ${ }^{11}$

\section{Results}

Out of the 1131 patients who completed the questionnaires, $878(77.6 \%)$ responded to the question about having had a terrifying or near-death experience and to the questions assessing the presence of PTSD. These subjects were analysed further. Of these, 194 (22.09\%) met the criteria for current PTSD. Survivor guilt was found in 336 responders (38.26\%).

As expected, the soldier-patients were quite youthful - 409 (46.58\%) were under 30 years of age, 212 (24.14\%) were aged 30 - 40, and 257 (29.27\%) were over 40. The majority ( $N=598,68.1 \%)$ were married, 265 (30.2\%) were single, and $15(1.7 \%)$ were separated or divorced. Only 2 were female.

The presence or otherwise of PTSD and survivor guilt were cross-tabulated with the other variables studied. Having PTSD was found to be significantly associated with witnessing the death of others during the trauma experience $\left(x^{2}=230.32, p\right.$ $<0.00)$, survivor guilt $\left(x^{2}=156.65, p<0.00\right)$, time spent in combat areas $\left(x^{2}=60.93, p<0.00\right)$ and cannabis use $\left(x^{2}=\right.$ $60.93, p<0.00)$. Survivor guilt was significantly associated with the death of others during the terrifying experience $\left(x^{2}=\right.$ $213.84, p<0.001$, avoidance of circumstances reminiscent of the experience $\left(x^{2}=156.66, p<0.00\right)$, time spent in combat areas $\left(x^{2}=25.41, p<0.00\right)$, current alcohol use $\left(x^{2}=9.07, p=0.03\right)$, lifetime use of the kinjus/gunpowder mixture $\left(x^{2}=4.87, p=0.02\right)$, and lifetime cannabis use $\left(x^{2}\right.$ $=5.16, p=0.021$.

In multivariate regression analysis, the independent variable that best predicted PTSD was the length of the time spent in combat mission ( $p=0.007$, odds ratio (OR) 3.32, confidence interval (CI): 1.31 - 4.52). For survivor guilt the significant predictors were witnessing death of others during the experience $(p=0.002, O R 3.39, \mathrm{Cl}: 1.56-7.36)$, and avoiding circumstances reminiscent of the unpleasant experience $(p=0.001, \mathrm{OR} 2.37, \mathrm{Cl}: 1.58$ - 5.61). The duration of combat exposure was not significant during the second analysis, but the sign associated with its bweight (0.054) was positive, indicating that the direction of relationship is such that the likelihood of having survivor guilt would increase as the duration of combat exposure increased.

\section{Discussion}

Our finding of a $22 \%$ prevalence rate revealed that PTSD was quite common among Nigerian soldiers exposed to combat in Liberia and Sierra-Leone. It is well known that whereas the PTSD rates for the general population may range between $1.2 \%$ and $2.7 \%,{ }^{3}$ the rates for those who have been exposed to combat range between $22 \%$ and $39 \%{ }^{2}$ The rates are usually even higher for those physically wounded in battle. ${ }^{12}$ The reason for the very high rate of survivor guilt may be related to the intra-group identification and cohesiveness that usually develops in combat-effective military units after several years of training together. Unfortunately, loss of 
men resulting from death or injury in battle is inevitable. For those who survive, witnessing the death of comrades is additional psychosocial stressor to the combat situation itself, and the survivor guilt that may result is understandably very distressing.

In our study the factors shown to be most closely associated with PTSD were witnessing the death of comrades, long duration of exposure to battle, and cannabis use. Similarly, factors associated with survivor guilt were witnessing the death of others during the experience, and the avoidance of circumstances reminiscent of the trauma. These are some of the well-described core features of PTSD. This similarity suggests that survivor guilt may occur on its own in a patient, as part of a PTSD syndrome or as part of a depressive syndrome, which is quite common among people who have been exposed to battle. In a study of Vietnam veterans, Nace et al. ${ }^{13}$ found a $32 \%$ prevalence rate for depression. Similarly, Jones $^{14}$ described a depressive syndrome called the 'old sergeant's syndrome', said to result from sustained combat in which many comrades died. Our finding of a relationship between PTSD and long duration of exposure to battle resembles the findings of other reports in the literature. ${ }^{12}$ It has been suggested that the soldier's adaptive capacity weakens as the duration of exposure to combat increases. ${ }^{12}$

Our data have shown that the presence of PTSD was related to cannabis use. On the other hand, survivor guilt was related to the use of alcohol, cannabis and the potent combination of the local brew (kinjus) and gunpowder. In Liberia, as in many war situations, these substances were used by soldiers to foster boldness, and during periods of low-intensity battle (or no battle) to counter boredom. ${ }^{15}$ It is well known that comorbidity of PTSD and other clinical conditions, especially affective disorders and alcohol and substance abuse, is not uncommon. ${ }^{15,16}$

Our study did not relate PTSD and survivor guilt to the type of duty performed while in the mission area (for example front-line or garrison duty). The fact that not all soldiers in the mission area reported experiencing a terrifying event suggests that not all of them filled combat roles. It was likely that only a small proportion of those experiencing PTSD symptoms sought help. Deliberate outreach to identify such persons could help to reduce the possible serious complications (such as suicide and homicide) and the other societal costs of the disorder.

Lastly, human carnage, brutality and atrocities of unimaginable magnitude were reported to have been committed by rebel troops in Liberia and Sierra-Leone, especially the latter. Youngsters under the influence of alcohol and other substances were said to have perpetrated most of these acts. It would be particularly interesting to study the phenomena of PTSD and survivor guilt among those soldiers following the end of the civil wars.

\section{References}

1. American Psychiatric Association. Diagnostic and Statistical Manual of Mental Disorders. 4th ed. Washington, DC: American Psychiatric Association, 1994.

2. Kessler RC, Sonnega A, Bromet E, Hughes M, Nelson C, Breslau N. Post traumatic stress disorder in a national co-morbidity survey. Arch Gen Psychiatry 1995; 52: 1048-1060.

3. Stein MB, Walker JR, Hazen AL, Forde DR. Full and partial posttraumatic stress disorder: findings from a community survey. Am J Psychiatry 1997; 154: 1114 1119

4. Kulka RA, Schlenger WE, Fairbank JA, et al. Trauma and the Vietnam Wa Generation: Report of Findings from the Vietnam Veterans Readjustment Study. New York: Brunner/Maze, 1990

5. Leighton AM, Lambo TA, Hughes CC, Leighton DC, Murphy JM, Macklin DP. Psychiatric Disorders Among the Yoruba. Ithaca: Cornell University Press, 1963.

6. Nechukwu STC. Psychiatry in Africa: Special problems and unique features. Transcultural Psychiatric Research Review 1991; 28: 169-218.

7. Majodina MZ, Attah-Johnson FY. Standardized assessment of depressive disorders in Ghana. BrJ Psychiatry 1983, 143: 442-446

8. Friedman MJ. Post-Vietnam syndrome: Recognition and management. Psychosomatics 1981; 22: $931-943$.

9. Kessler RC. Post traumatic stress disorder: the burden to the individual and to society. J Clin Psychiatry 2000; 61: Suppl 5, 4-12.

10. Weathers F W, Litz ET, Huska JA, Keane TM. PCL-C for DSM 4. Boston: National Center for PTSD, Behavioral Sciences Division, 1994

1 1. Adelekan ML, Odejide OA. The reliability and validity of the $\mathrm{WHO}$ student drug-use questionnaire among Nigerian students. Drug Alcohol Depend 1989; 24: $245-$ 249.

12. Buydens-Branchey L. Noumair D, Branchey M. Duration and intensity of combat exposure and post-traumatic stress disorder in Vietnam veterans. J Nerv Ment Dis 1990; 178: 582-587

13. Nace EP, Myers AL, O'Brien L, et al. Depression in veterans two years after Vietnam. Am J Psychiatry 1977; 134: 167-170.

14. Jones FD. Combat psychiatry in modern warfare. Proceedings of the World Psychiatric Association, Section of Military Psychiatry International congress Meeting Lagos, Nigeria, September 1979

15. Okulate GT. Patterns and timings of neuro-psychiatric casualties in war. The Liberian experience. Proceedings of the 5th World Congress of the International Association for Emergency Psychiatry, Belgium, November, 1998

16. Bleich A. Koslowsky M, Dolev A, Lerer B. Post traumatic stress disorder and depression. An analysis of co-morbidity. Br J Psychiatry 1997; 170: 479-482.

Reprinted from the South African Medical Journal (2006: 96: 144-146). 